\title{
URBAN LAND USE POLICIES FOR EFFICIENT AUTONOMOUS ON-DEMAND TRANSPORTATION - A CASE STUDY ON THE JAPANESE ISLAND OF IZU OSHIMA
}

\author{
LUKAS D. PÖHLER ${ }^{1}$, YASUSHI ASAMI ${ }^{2} \&$ TAKASHI OGUCHI ${ }^{3}$ \\ ${ }^{1}$ Department of Electrical and Computer Engineering, Technical University of Munich, Germany, \\ http://orcid.org/0000-0002-6401-5557 \\ ${ }^{2}$ Department of Urban Engineering, The University of Tokyo, Japan \\ ${ }^{3}$ Institute of Industrial Science, The University of Tokyo, Japan
}

\begin{abstract}
This paper introduces an agent-based simulation approach to model current and future spatial mobility demand based on activity profiles under different urban land use policies. Further, mobility provision for young and elderly people through a system consisting of shared, on-demand autonomous vehicles (AVs) is proposed and evaluated. We use a generalized optimization approach including investment, driving, and social costs to determine the optimal number of vehicles. Future demographics of the population are simulated through a cohort analysis where migration based on historical data is taken into account. The method is applied to the case of Izu Oshima, a Japanese island strongly affected by demographic change and comprising of a high number of immobile citizens. The promotion of settlement in vacant houses in different areas of Izu Oshima through urban land use policies is simulated and compared with respect to urban sprawl, spatial mobility demand, and the cost of mobility provision. The results show that land use policies have a big potential to lower the cost of transportation. We further show that their effect is stronger for shared electric $\mathrm{AVs}$ than for conventional transportation systems. Keywords: Agent-based modelling, Autonomous vehicles, Demand forecasting, Demographic change, Land use planning and Public transportation.
\end{abstract}

\section{INTRODUCTION}

Demographic change, urbanization, rising energy costs and sustainability concerns increasingly question the efficiency of transportation systems with private vehicles. Most personal vehicles are over-engineered for the majority of trips regarding performance and speed. Further, they are underutilized with respect to available seats and are parked $90 \%$ of the time on average [1]. Rural and depopulating areas in particular often lack sufficient public alternatives to private car usage due to unprofitable operation of bus or train routes with low demand. In recent years, shared mobility systems are gaining attractiveness and contribute to increased utilization of vehicles and expand access to public transit. Due to recent higher levels of vehicle automation and their successful deployment in pilot projects, growing attention is being paid to autonomous vehicles (AVs) not only for private usage but increasingly as an alternative to taxis [1] or as part of public transportation systems for low-demand purposes in an autonomous mobility on-demand (AMoD) setting [2]. To model AMoD systems, agent-based models (ABMs) are applied to simulate real-time demand creation and vehicle movement. Different ABMs can be characterized by the level of detail in the simulation and a variety of approaches exists [3]. Frameworks such as SimMobility simultaneously model demand and supply and their interactions on different time scales ranging from short-term travel behaviour simulation over daily activity patterns to long-term land development and demographic change [4].

AMoD will most likely have a strong impact on future cities and therefore requires special consideration [5]. AVs can support urban development strategies such as social inclusiveness 
and attractiveness of certain areas if their introduction is carefully planned [6]. Understanding the long-term impact of $\mathrm{AMoD}$ and its relation to land use planning is crucial to successfully apply these systems. In 2014, the Japan Ministry of Land, Infrastructure, Transport and Tourism (MLIT) presented its Grand Design of National Spatial Development towards 2050 [7]. Major challenges of Japan are an aging society, natural disasters and demographic shrinkage, particularly in rural areas. For rural regions, the Grand Design proposes small stations which serve as community service hubs for daily shopping, medical services and education to surrounding villages. Sustainable transportation between villages and a hub should be achieved by connected and automated driving technologies [8].

In this work, we develop a shared mobility concept with electric AVs against the background of the Japanese Grand Design. We focus our research on students and elderly people on the island of Izu Oshima (伊豆大島) and propose self-driving shuttles as an efficient and cost attractive AMoD. To achieve the goals of the Japanese Grand Design, we compare three different land use policies to promote the settlement of migrating people in vacant houses in certain areas of the island. We apply a long-term ABM based on simulated spatial mobility demand for the urban facilities schools, supermarkets and the medical clinic considering the demographic change. In the ABM, we link individual demand with simulated mobility supply through AVs. After the challenges of our use case for Izu Oshima have been presented in Section 2, Section 3 outlines the urban facilities on the island and introduces three land use policies as possible scenarios of future settlement on the island. The details of the model framework and its components are shown in Section 4. Results from the simulation are evaluated in Section 5, and the conclusion is given in Section 6.

\section{PROBLEM STATEMENT}

The island of Izu Oshima is situated about $120 \mathrm{~km}$ south of Tokyo in the Philippine Sea and affected by the demographic change and depopulation. This leads to dispersion of residential land, house vacancy and an insufficient public transportation system. Based on these challenges and negligible boundary effects, this island was chosen for our study. Where not mentioned otherwise, statistics in this chapter are from the Oshima government [9].

\subsection{Demographic Change and Population Decline}

Within the last 10 years, the island has experienced a steady population decline from 8,840 in 2007 to 7,647 in 2018. This is mainly based on the emigration of young people from lacking education and job opportunities. Having left the island, less than $90 \%$ of the people return. In $2017,38.2 \%$ of the population was over 65 years old and only $10.3 \%$ younger than 15 years. Because of the strong depopulation, the island faces a high vacancy rate of residential houses (13.2\% in November 2016). Almost no new residential houses are constructed on the island. The average number of persons in a household declined from 1.84 in 2007 to 1.68 in 2018 and high dispersion of residential land limits agricultural land [10].

\subsection{Transportation System}

The main public transport on Izu Oshima is a bus with ticket prices between 130 and 890 yen (100 yen equal USD 0.91 in 2018). As a result of fixed routes and a sparse schedule, the bus is not very attractive to citizens and private vehicles are the major means of transportation on the island. This poses a problem for immobile citizen groups such as elderly and underage 
people. Each of the three primary schools on the island has a school bus. The yearly operation costs of the school buses are 20 million yen according to the town office. An interview with a school principal on the island revealed that around $20 \%$ of non-primary school students commute by bike to school, the rest of the students are driven by their parents, use the regular bus or walk. In 2018, a door-to-door on-demand elderly vehicle was introduced and since then it is frequently demanded. The expected operation costs for the vehicle are 10 million yen per year and one ride costs 3,000 yen. Apart from the public transportation, taxis are available on the island with a minimum charge of 680 yen within the first $2 \mathrm{~km}$.

To conclude, major challenges on Izu Oshima are the increasing mobility demand of immobile groups, lack of attractiveness, dispersion of residential land, and a high vacancy rate of residential houses. In 2016, the government of Oshima proposed several measures to tackle the challenges on the island. Besides simplification of resettlement and assistance in migration to the island, vacant house usage is promoted. Concerning transportation, easy-to-use transportation systems should be established through on-demand services. Therefore, we evaluate the potential of a shared autonomous on-demand transportation system consisting of electric vehicles. This approach seems promising to achieve an accessible, sustainable, and cost-efficient transportation system for the citizens and might increase the attractiveness of the island. Together with appropriate land use policies, dispersion of residential land on the island might be reduced and a densification of settlements achieved, resulting in reduced commuting distances and therefore lower transportation costs for residents.

\section{BUILT STRUCTURE AND LAND USE POLICIES}

In this section, we first give an overview of the urban facilities on Izu Oshima included in our study. In the second part, we introduce the three scenarios, with one being business-as-usual and two consisting of land use policies to promote specific areas for settlement.

\subsection{Urban Facilities}

We consider the urban facilities schools (primary, junior high and high schools), supermarkets and the medical clinic, because they are popular destinations for school children and the elderly. The average number of patients attending the medical clinic per day from 2015 to 2017 was 328, with around $70 \%$ being elderly people, $20 \%$ adults and $10 \%$ children. Due to declining student numbers, the primary schools have been relocated to the junior high schools. The locations of the urban facilities are shown in Fig. 1(a) together with two possible locations for overnight parking and charging of the autonomous fleet, selected according to free land or existing parking spaces. Two thirds of the vehicle fleet are assigned to the car parking 1 , the rest to car parking 2 .

\subsection{Land Use Policies}

Land use policies either restrict or incentivize a particular land use. Restricting the construction of new houses or using the land of vacant houses might stop urban sprawl, reduce the number of vacant houses and achieve a compact built structure. Subsidizing the cost of immigration to promote migration is applied by islands in the prefecture of Kagoshima [11]. Further, several cities affected by demographic change promote settlement of citizens in particular areas to achieve a compact city development. The Japanese city of Toyama subsidizes 

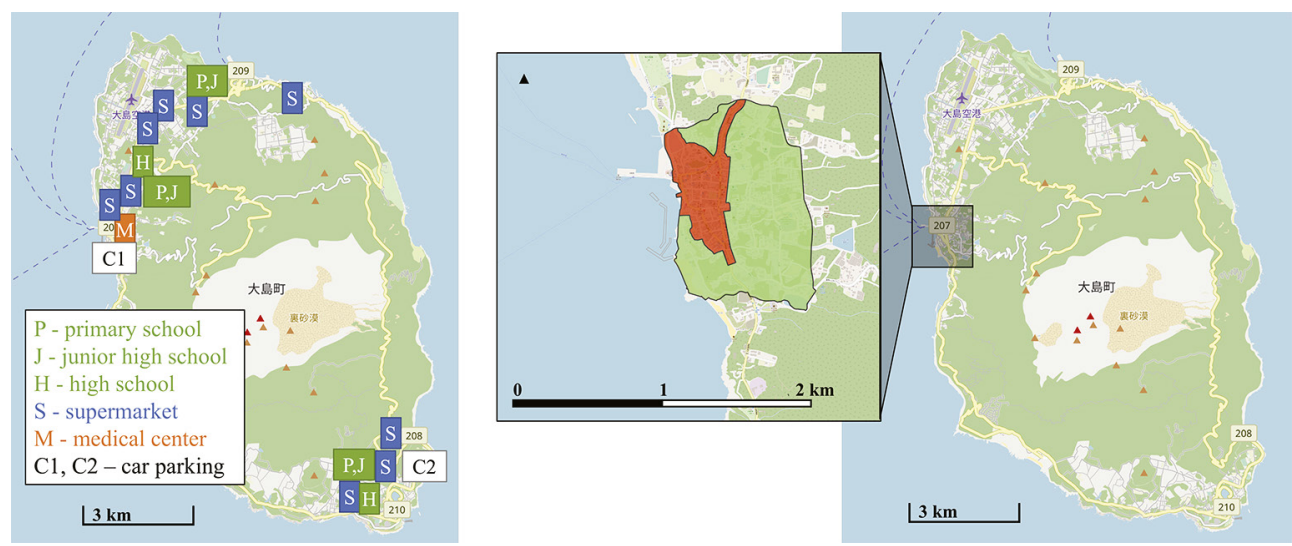

Figure 1: Maps of Izu Oshima. (a) Location of the urban facilities with possible car parking spaces; (b) Land use policy in Scenario 2 depicted in orange.

the purchase and rent of houses close to public transport stations or in the urban centre and promotes the development of apartments there [12]. It can be expected that further rural municipalities and islands will offer such incentives in the future.

In our study, we simulate three scenarios and assume a compliance rate of $50 \%$ with the land use policies in Scenario 2 and Scenario 3. The first scenario is business-as-usual, with no restriction or promotion of any particular land use. This means that all vacant houses are randomly inhabited by immigrating individuals. The second scenario City planning concept is based on a land use policy from the municipality. It demands the construction of concrete houses in the core residential area shown in Fig. 1(b). This city planning concept aims at making the city resilient against fire disasters from volcanic activity on the island and thus the policy could densify the residential houses around the core of the city centre and lead to a more compact city structure. Scenario 3 Closeness to urban facilities promotes residential settlement within a radius of $400 \mathrm{~m}$ around the urban facilities of supermarkets and the medical clinic in Fig. 1(a). The municipality could promote the movement of people into the designated residential areas or restrict other areas in order to achieve the land use policies.

\section{MODEL APPROACH}

As outlined in Section 1, ABMs allow to flexibly simulate mobility demand and supply through AVs in an AMoD transportation system. We adopt the framework in [13] by neglecting traffic congestion effects, which is a mild assumption on Izu Oshima, and include the simulation of the demographic change from which the demand is predicted. Further, we neglect induced traffic. Our model consists of four stages as depicted in Fig. 2. From the initial demographics and population distribution in 2018, we predict the demand from individual activity profiles. Afterwards, we simulate the AMoD, where self-driving vehicles collect and drive customers to their destinations. After each year, the demographic change and migration to the island is predicted under the specific land use policy. Finally, the process starts again with the updated population demographics and distribution on the island. In the following of this section, we outline each stage of our model in more detail. 


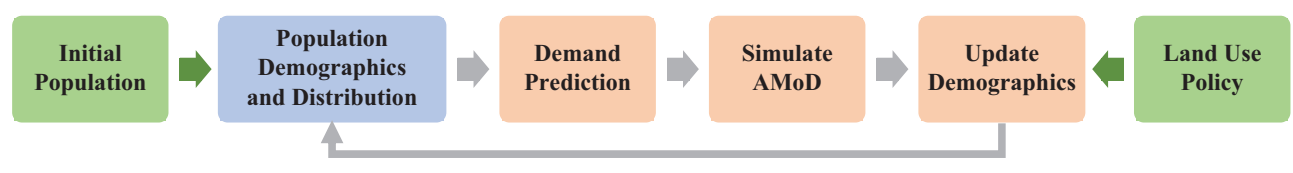

Figure 2: Framework of the agent-based model.

\subsection{Initial Population Distribution}

If not otherwise stated, all demographic data in this section are retrieved from [14]. We base the initial population of Izu Oshima on Tokyo Census Data from 2015. The population is spatially distributed among all of the buildings on the island and the distribution within a district is achieved by randomly assigning individuals to the houses conforming to the number of vacant houses and the average number of households per house. We initially update the demographics from 2015 until 2018 according to the approach in Section 4.4.

\subsection{Demand Prediction}

The probability of a certain trip is predicted every minute for each individual. Activity profiles for persons are based on the Japanese Personal Trip Survey 2008 [15]. Since the survey is only undertaken on the mainland, we use the average of Tateyama and Yokosuka, two regions on the mainland close to Izu Oshima. By normalizing the trip numbers for a purpose, we calculate the probability density function $p_{\text {act }}(t)$ that a certain activity takes place during a particular minute $t$ of the day. The normalized trips from the dataset are shown in Fig. 3. For supermarket trips, we take the survey data on leisure both with and without home as origin. Hospital trips are based on trip data with the label other.

Travel requests are restricted to the opening hours of the supermarkets ( 9 am to $7 \mathrm{pm}$ ) and the medical clinic (10 am to $9 \mathrm{pm}$ ). Based on interviews on the island, we assume that students leave the primary school after $2 \mathrm{pm}$, the junior high school after $3 \mathrm{pm}$ and the high school after $4 \mathrm{pm}$. The probability of a trip including opening hours can be expressed as follows:

$$
\hat{p}_{a c t}(t)=w_{a c t}(t) \cdot p_{a c t}(t)
$$

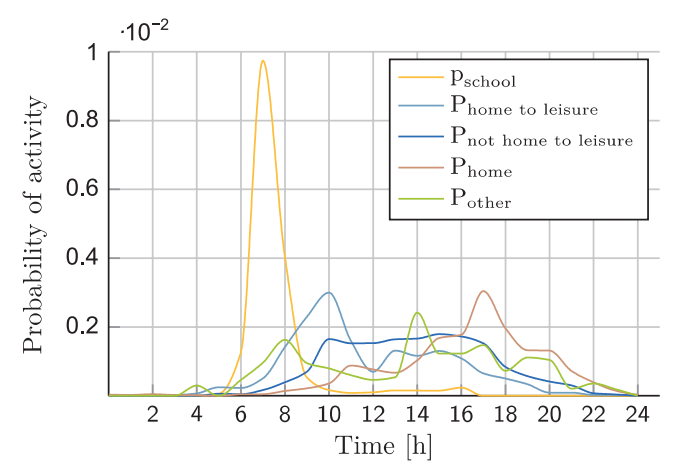

Figure 3: Normalized travel demand of Tateyama and Yokosuka from the Trip Survey 2008. 
where $\omega_{a c t}(t)$ is a weight for scaling the number of trips. We set $\omega_{\text {act }}(t)=0$ outside the opening hours or school times and $\omega_{a c t}(t)=c_{a c t}$ such that the total number of trips and share between the groups according to cumulative data (number of patients in the medical clinic, their age share and the expected number of supermarket trips) are obtained in the simulation. We assume that students make one supermarket trip by car every 5th day and that elderly people make one every 2 nd day. We allow trip chains to take place based on survey data introduced above and assume that the half of hospital trips are in trip chains.

\subsection{Simulate AMoD}

We model roads on the island as a graph with nodes at road intersections extracted from OpenStreetMap. The Dijkstra algorithm is applied to determine the shortest routes and the vehicle velocities are modelled through the node density of the graph (street intersections per trip length in $\mathrm{km}$ ) with $30 \mathrm{~km} / \mathrm{h}$ if the density is smaller than 5 nodes $/ \mathrm{km}, 12 \mathrm{~km} / \mathrm{h}$ if the density is higher than 10 and linearly in between. This model showed good conformity with random checks in GoogleMaps. Demands are queued up and the closest empty vehicle is assigned on a first-come-first-served basis until the demand queue is empty. If all vehicles are booked or already on a ride with customers, the remaining demands stay in the queue for the next time step. We allow ride sharing by up to four persons if another person has the same destination and no detour is necessary for pick-up. At $10 \mathrm{pm}$, all free vehicles are sent back to their closest car park until the car park is full. Then vehicles are sent to the other car park.

\subsection{Update Demographics}

To estimate future demographics on Izu Oshima, we apply a cohort analysis approach. We define the population $P_{i, j}^{a}$ as the number of individuals with gender $i(i=1$ male, $i=2$ female) and age $j$ in year $a$. The initial population from the 2015 census data is denoted as $P_{i, j}^{2015}$. For a consecutive year $a+1$, the population is updated according to the following rules:

$$
\begin{aligned}
\text { Survival: } \tilde{P}_{i, j}^{a+1} & =\gamma \alpha_{i j} P_{i, j-1}^{a} \\
\text { Birth: } P_{i, 0}^{a+1} & =\beta \sum_{j=15}^{44} b_{j} P_{2, j}^{a} \\
\text { Migration: } P_{i, j}^{a+1} & =\tilde{P}_{i, j}^{a+1}+\Delta P_{i, j} .
\end{aligned}
$$

The survival rates $\alpha_{i j}$ are obtained from the 2017 Statistical Handbook of Japan [16]. We consider a non-uniform distribution of mothers' ages as proposed in [17], with $b_{j}$ representing the probability of giving birth at a certain age according to data in [16]. Adaption parameters $\beta$ and $\gamma$ are adjusted to fit historical numbers of births and deaths in the years 2014-2017. The gender of a newborn child is determined according to the expected values for the sex ratio at birth in Japan between 2018 and 2030 from [18]. The demographic distribution of the migrating individuals $\Delta P_{i, j}$ is determined by the average deviation from predicted and true demographics in the years 2014 to 2018. We assume that the migration numbers of the year 2017 represent the number of future yearly migrants. Newborns are assigned to the house of the mother giving birth. The individuals that die or move away from the island are 
chosen based on their ages, but the particular individual in that age group is chosen randomly. Migrants to the island move into a vacant house or flat depending on the urban land use policy as described in Section 3.2. The initial spatial population distribution of Izu Oshima in 2018 is shown in Fig. 4(a).

\section{EVALUATION}

In this section, we present results of our model starting with the predicted demographics and population distribution. After this, the mobility demand in 2018 is shown, followed by resulting trips of AVs and the spatial analysis of trips. We further evaluate the costs of the proposed electric AMoD in 2030 for the three scenarios and compare it to the current transportation system with school buses and conventional personal vehicles.

\subsection{Future Demographics}

The predicted population of Izu Oshima in January 2030 is with 5,716 individuals drastically smaller compared to the simulated number of 7,669 for January 2018. Split into age groups, we experience an increase in the share of elderly people above 65 (from $35.2 \%$ to $36 \%$ ) and adults (from $51.5 \%$ to $52.8 \%$ ) and a decline in the number of underaged (from $13.3 \%$ to $11.2 \%$ ). The absolute decline of underaged from 1,020 in 2018 to 640 in 2030 is remarkable.

\subsection{Population Distribution}

The land use policy impacts the future spatial distribution of residents on the island. In Scenario 1 (business-as-usual), the migrating residents are modelled to randomly select a vacant house, which results in a balanced spatial population distribution. The promotion of settlement in the core residential area in Scenario 2 (City planning concept) is shown in Fig. 4(b) and results in a clear concentration of the population on the western coastline of the island. The outcome of Scenario 3 (Closeness to urban facilities) leads to an agglomeration of residents around urban facilities. Since the compliance rate is only $50 \%$, we still experience settlement outside the promoted areas.

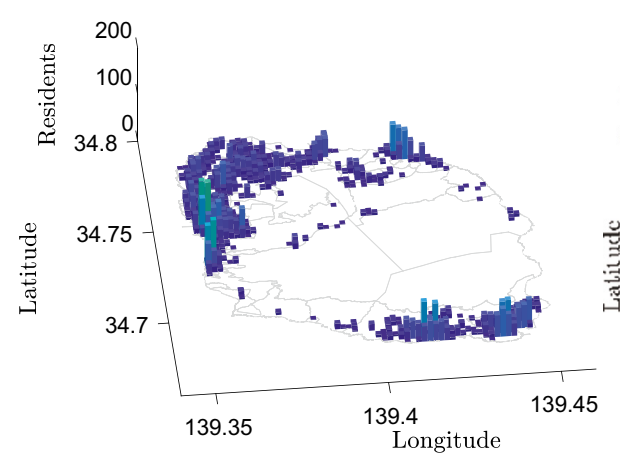

(a)

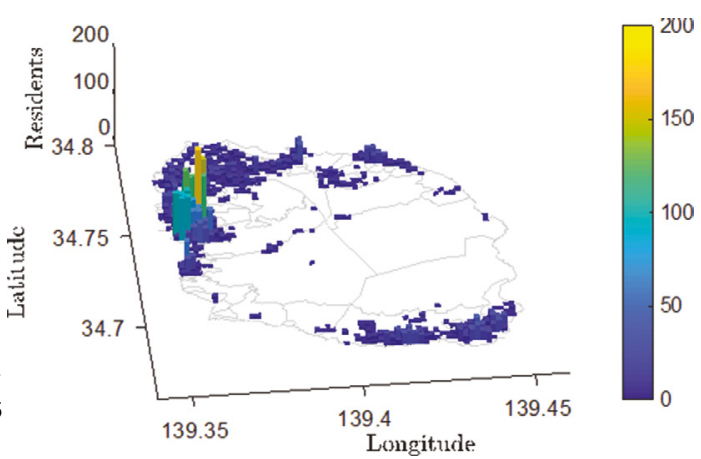

(b)

Figure 4: Predicted population on Izu Oshima. (a) In 2018; (b) In 2030 under Scenario 2. 


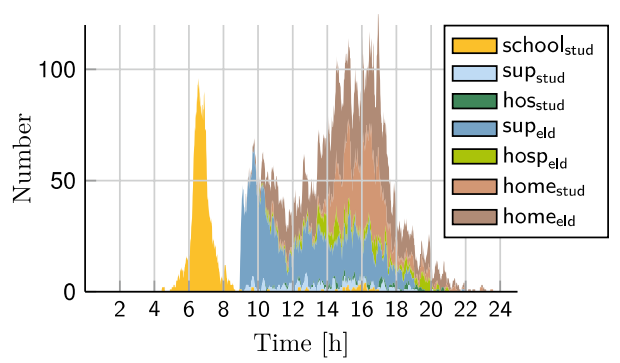

(a)

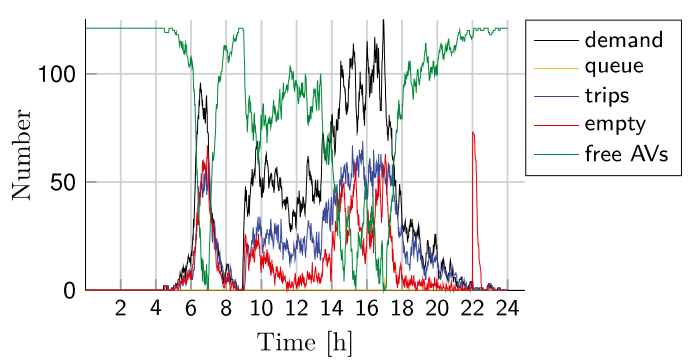

(b)

Figure 5: Simulation results for 1 day in 2018. (a) Demanded trips by type and group; and (b) accumulated and queued demand, trips, empty rides and free vehicles.

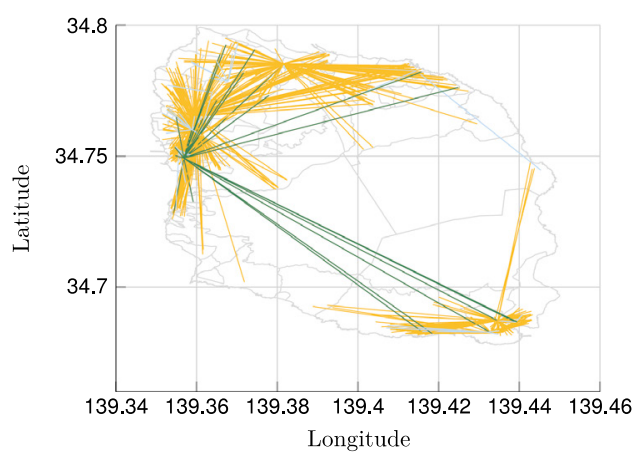

(a)

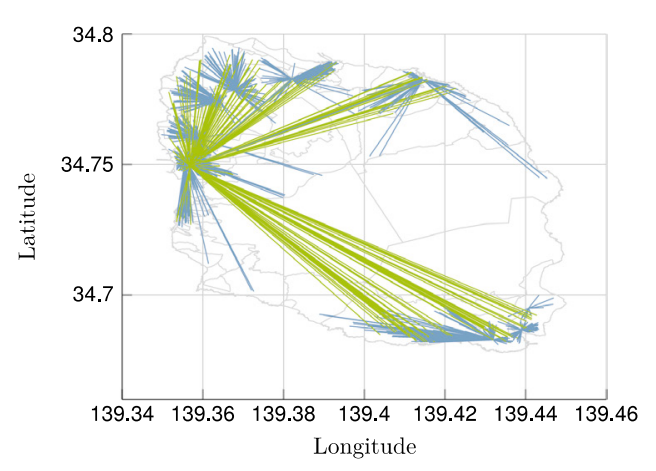

(b)

Figure 6: Connected trip origins and destinations in 2018 with hospital trips in green, school trips in orange and supermarket trips in blue. (a) Students and (b) elderly.

\subsection{Mobility Demand in 2018}

The mobility demand of students and elderly people per activity over 1 day in 2018 is shown in Fig. 5(a). A high demand for school trips in the morning occurs and shopping and hospital trips begin at around 9 and $10 \mathrm{am}$, respectively. A high number of home trips with peaks at 2, 3 and $4 \mathrm{pm}$ is visible when students return home from school.

Fig. 5(b) shows the accumulated demand and vehicle trips, empty rides and free AVs resulting from the AMoD simulation with a full replacement of the school buses and personal vehicles of elderly residents with $121 \mathrm{AVs}$. As shown in Section 5.5, this number of AVs is optimal with respect to the total cost of transportation. Queuing of a few passengers occurs in the morning peak when students go to school and in the afternoon when the students leave school. The high number of empty rides at $10 \mathrm{pm}$ is due to the redistribution of the AVs to car parks for charging and overnight stays. Concerning the spatial mobility demand, Fig. 6(a) and (b) shows the connected origins and destinations of student and elderly people trips in 2018 with colours according to Fig. 5(a). Home trips are excluded to improve visibility. As it can be seen, hospital trips have a big impact on the total distance travelled. 


\subsection{Cost Evaluation}

Since the results of citizen surveys show that the acceptance of AMoD depends not only on travel cost, based on investment costs $C_{i}$ and driving costs $C_{d}$, but also on travel time and waiting time [19], we include social costs $C_{s}$ in our analysis of the proposed transportation system. Therefore, the total cost of our transportation system per year is given as:

$$
C^{\text {system }}=C_{i}+C_{d}+C_{s} .
$$

For evaluating the costs in the following, we simulate one typical weekday for the respective year and multiply the costs by a factor of 260 to get the total cost for all workdays per year.

\subsubsection{Investment Costs}

Based on statistics on the average service life of passenger cars and buses in Japan in the last years [20,21], we assume that one conventional vehicle needs to be replaced once in the timespan of our simulation of 13 years. For the conventional transport system, we set the investment cost of a conventional personal vehicle as one million yen, and for the purchase cost of one new school bus we take the past cost of school buses on Izu Oshima of 9 million yen. We neglect the vehicle costs for parents who drive their children to school. For the proposed AMoD, we assume that the price of one four-seater $\mathrm{AV}$ is 10 million yen, which is a generous assumption compared to other works [22]. We distribute the investment costs uniformly over the simulation horizon of 13 years.

\subsubsection{Driving Costs}

Total driving costs in our model are defined as

$$
C_{d}=\sum_{\text {trips }}\left(c_{d} \cdot t_{\text {drive }, m}\right)
$$

with every trip having a certain means of transportation $m$ with respective driving costs $c_{d}$ and trip time $t_{\text {drive }, m}$. Driving costs of private vehicles result from $180 \mathrm{yen} / \mathrm{L}$ fuel costs and a consumption of $10 \mathrm{~L} / 100 \mathrm{~km}$. For the electric $\mathrm{AVs}$, we set an industrial electricity tariff from Tepco in 2018 with $12 \mathrm{yen} / \mathrm{kWh}$ and specifications from the electric vehicle Nissan Leaf $\mathrm{BEV}$ with $0.21 \mathrm{kWh} / \mathrm{km}$. Operating costs of the door-to-door vehicle are 10 million yen/year and of the primary school buses 20 million yen/year. Persons walk distances under $200 \mathrm{~m}$ with $5 \mathrm{~km} / \mathrm{h}$. Above, primary school students take the school bus. $20 \%$ of the other students commute by bike $(10 \mathrm{~km} / \mathrm{h})$ if the distance is below $1.5 \mathrm{~km}$ while the rest is driven. Elderly people either take the door-to-door vehicle (a total of $3 \mathrm{~h}$ of trips with customers per day), are driven, or drive by themselves with the same probability. In the AMoD model, we assume that all the trips except walking and cycling are covered by the shared AVs.

\subsubsection{Social Costs}

To estimate the social costs of waiting times $t_{\text {wait, } g}$ and driving times $t_{\text {travel, }, g}$, we use the waiting time values $c_{g}$ and travel time values $c_{m, g}$ for low congestion from [23] with age group $g$. They indicate the value of waiting and travel time as a percentage of prevailing wages, which we set as minimum wage of 2018 in Tokyo prefecture (958 yen/h). Resulting average waiting and travel times of passengers from our simulation are shown in Fig. 7. The waiting time values $c_{g}$ are discounted by $20 \%$ because the arrival time of the on-demand vehicle is known, and we consider the average of the waiting time value of seating and standing in good waiting conditions. Waiting time is neglected for the conventional transportation system. We further consider the social cost of the walking and cycling trips and include them as social 


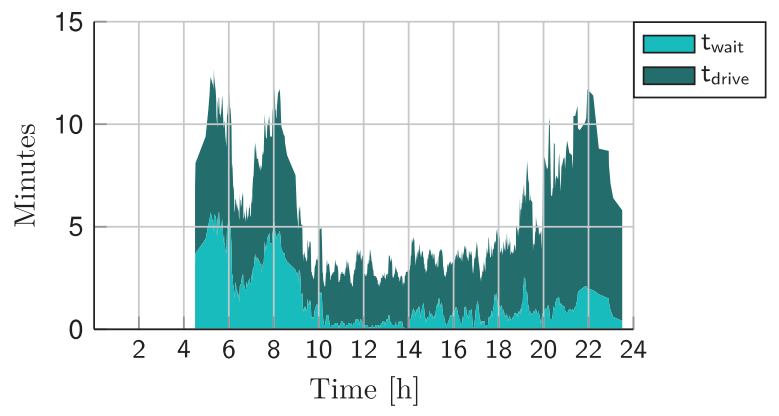

Figure 7: Waiting and travel times in each minute for 1 day in 2018 with 121 AVs.

cost of driving. In the case where a student or elderly person is driven by a relative, we sum their travel time values. Thus, social costs of mobility are

$$
C_{s}=\sum_{\text {trips }}\left(c_{g} \cdot t_{\text {wait }, g}+c_{m, g} \cdot t_{\text {travel }, g}\right)
$$

\subsection{Results of Evaluation of Costs in 2018 and 2030}

Table 1 shows results of the cost evaluation in 2018. The average trip cost $\bar{C}_{\text {trip }}$ is calculated by distributing $C^{\text {system }}$ over the total number of yearly trips. The cost optimal system $\mathrm{AMoD}_{\text {opt }}$ consists of $121 \mathrm{AVs}$. Comparing $\mathrm{AMoD}_{\text {opt }}$ with AMoD' (131 AVs and no queuing of demands), shows that the waiting time and thus the social costs of waiting can be decreased with more AVs, but results in higher investment and system costs. The system costs of $\mathrm{AMoD}_{\text {opt }}$ and $\mathrm{AMoD}$ ' are lower than the conventional system with buses and private cars.

In 2030, less AVs will be necessary because of depopulation. The results of the cost comparison between the conventional and the proposed AMoD transportation systems are shown in Table 2 for each scenario optimized for system cost $C^{\text {system }}$. This optimization

Table 1: Comparison of costs and waiting times in 2018 between the current conventional transportation system, the optimized $\mathrm{AMoD}_{\text {opt }}$ and $\mathrm{AMoD}^{\prime}$ with more $\mathrm{AVs}$.

\begin{tabular}{lccc}
\hline \multirow{2}{*}{ Category } & \multicolumn{3}{c}{ Mobility costs and times in 2018 } \\
\cline { 2 - 4 } & Conventional & $\mathrm{AMoD}_{\mathrm{opt}}$ & $\mathrm{AMoD}$ \\
\hline Number of AVs & 0 & 121 & 131 \\
Investment cost $C_{i}\left(10^{6}\right.$ yen $)$ & 210 & 93.1 & 101 \\
Driving cost $C_{d}\left(10^{6}\right.$ yen $)$ & 64.8 & 5.87 & 5.81 \\
Waiting time $t_{\text {wait }}\left(10^{3} \mathrm{~h}\right)$ & 0 & 4.55 & 4.42 \\
$C_{s \text {,driving }}\left(10^{6}\right.$ yen $)$ & 66.5 & 33.6 & 33.8 \\
$C_{s, \text { waiting }}\left(10^{6}\right.$ yen $)$ & 0 & 19.3 & 16.6 \\
Social cost $C_{s}\left(10^{6}\right.$ yen $)$ & 66.5 & 52.9 & 50.3 \\
$C^{\text {system }}\left(10^{6}\right.$ yen $)$ & 340.8 & 151.8 & 156.91 \\
$\bar{C}_{\text {trip }}$ (yen $)$ & 293.5 & 130.7 & 137.66 \\
\hline
\end{tabular}


Table 2: Comparison of costs and waiting times in 2030 between the current conventional transportation system and the optimized AMoD under the scenarios.

\begin{tabular}{|c|c|c|c|c|c|c|}
\hline \multirow{3}{*}{ Category } & \multicolumn{6}{|c|}{ Mobility costs and times in 2030} \\
\hline & \multicolumn{2}{|c|}{ Scenario 1} & \multicolumn{2}{|c|}{ Scenario 2} & \multicolumn{2}{|c|}{ Scenario 3} \\
\hline & Conv & AMoD & Conv & AMoD & Conv & AMoD \\
\hline Number of AVs & 0 & 83 & 0 & 76 & 0 & 81 \\
\hline Investment cost $C_{i}\left(10^{6}\right.$ yen $)$ & 160 & 63.8 & 160 & 58.5 & 160 & 62.3 \\
\hline Driving cost $C_{d}\left(10^{6}\right.$ yen $)$ & 53.8 & 3.84 & 50.2 & 3.25 & 50.5 & 3.39 \\
\hline Waiting time $t_{\text {wait }}\left(10^{3} \mathrm{~h}\right)$ & 0 & 4.69 & 0 & 3.90 & 0 & 4.08 \\
\hline$C_{s, \text { driving }}\left(10^{6}\right.$ yen $)$ & 45.0 & 22.8 & 42.1 & 21.1 & 39.7 & 20.3 \\
\hline$C_{s, \text { waiting }}\left(10^{6}\right.$ yen $)$ & 0 & 11.7 & 0 & 10.8 & 0 & 10.4 \\
\hline Social cost $C_{s}\left(10^{6}\right.$ yen $)$ & 45.0 & 34.5 & 42.1 & 31.9 & 39.7 & 30.7 \\
\hline$C^{\text {system }}\left(10^{6}\right.$ yen $)$ & 259.3 & 102.2 & 252.6 & 93.63 & 250.57 & 96.42 \\
\hline $\bar{C}_{\text {trip }}($ yen $)$ & 330.0 & 130.0 & 315.9 & 117.1 & 334.3 & 128.6 \\
\hline
\end{tabular}

results in $83 \mathrm{AVs}$ for Scenario 1, $81 \mathrm{AVs}$ for Scenario 3 and $76 \mathrm{AVs}$ for Scenario 2 which has the lowest total cost among the scenarios. In all three scenarios of our model, the $\mathrm{AMoD}$ is cheaper than the conventional transportation system. The main reasons are shared investment costs of vehicles and reduced driving costs from lower electricity costs and consumption of electric vehicles. Further, the social costs of driving under the conventional system with self-driving or adult drivers are roughly twice as high as those under the AMoD. Even with additional waiting costs, the total social costs of the AMoD are lower in every scenario.

The land use policies have a stronger impact on the AMoD system in reducing the total costs than the conventional system. As expected, Scenario 1 has the highest driving costs from high total driving distances. The AMoD in Scenario 3 also has higher investment and driving costs than Scenario 2. Because of the impact of long trips to the medical clinic (refer to Fig. 6), Scenario 2 is most efficient with respect to total system cost since the hospital is included in the smaller residential area promoted in this policy.

We need to remark that for a comprehensive assessment of the full mobility costs also adults and further urban facilities should be considered. However, our results show that the combination of different age groups and use cases for shared mobility - here driving students and elderly people - leads to a higher utilization of vehicles and lower transport costs.

A further advantage of AVs could be the reduction of traffic accident costs by more reliable driving behaviour [24]. To roughly estimate the impact of this aspect, we divide the estimated total economic loss from Japanese accidents in 2012 (6.33 trillion yen) [25] by the 71.43 billion vehicle kilometres travelled in 2015 [26]. This leads to an estimated average accident cost of $88.6 \mathrm{yen} / \mathrm{km}$. Considering 2018, in which elderly people and students accounted for 2.37 million $\mathrm{km}$ in our model, we could expect total traffic accident costs of 198.7 million yen. Since to date no experience on accident rates of AMoD fleets exists, the expected reduction of traffic accidents cannot be predicted reliably. However, we see that the impact of even a small reduction of traffic accidents would strongly impact the total system cost. 


\section{CONCLUSION}

This work shows a framework for incorporating demographic change and long-term prediction of spatial mobility demand into an agent-based mobility model. By applying this model to the Japanese island of Izu Oshima, we show the feasibility and cost benefits of a shared fully autonomous mobility system in contrast to a conventional mobility system with school buses and personal vehicles in 2018 and 2030 for schoolchildren and elderly people. We model their mobility demand for schools, supermarkets and the medical clinic.

We determine the number of AVs using a generalized optimization approach for investment, driving and social costs of waiting and travel times. Further, we demonstrate the positive impact of land use policies on the densification of residential land which improves the efficiency and cost reduction of our mobility system. We evaluate three different land use policies by modelling residential location choices with a predefined compliance rate to the policies. The saved costs of the transportation system could be used to financially incentivize the settlement of people in the designated areas. Most likely, the attractiveness of an area increases with the introduction of a shared autonomous mobility system and it seems promising to assess this attractiveness gain for regions. This would support decision-makers in local governments in the policy-making process and financial assessment of investments in innovative mobility concepts. The promotion of particular areas for settlement seems promising to support transport-oriented development. Together with the introduction of shared and autonomous mobility systems, cost-efficient mobility can be sustained in depopulating areas with a drastically aging society.

We motivate future research with a more comprehensive cost model including the mobility demand of adults, induced traffic and economic impact of traffic accidents. Further, a moredetailed model of the rate of compliance with land use policies and change of the attractiveness of a region by autonomous mobility seems promising. Our framework could also be applied in future studies for finding strategies on cost optimal investment in AVs for a gradual transformation of the transportation system.

\section{ACKNOWLEDGEMENTS}

The authors would like to thank the Oshima Town Office and Medical Clinic for providing useful information and data, Professor Daichi Furuhashi of Aoyama Gakuin University for providing GIS data of Izu Oshima and Professor Kimihiro Hino and the members of the University of Tokyo Housing and Urban Analysis Laboratory for their comments.

\section{REFERENCES}

[1] Pavone, M., Autonomous mobility-on-demand systems for future urban mobility. Autonomous Driving: Technical, Legal and Social Aspects, eds. M. Maurer, J.C. Gerdes, B. Lenz \& H. Winner, Springer-Verlag: Berlin and Heidelberg, pp. 387-404, 2016.

[2] Shen, Y., Zhang, H. \& Zhao, J., Integrating shared autonomous vehicle in public transportation system: a supply-side simulation of the first-mile service in Singapore. Transportation Research Part A: Policy and Practice, 113, pp. 125-136, Jul. 2018.

[3] Berrada, J. \& Leurent, F., Modeling transportation systems involving autonomous vehicles: a state of the art. Transportation Research Procedia, pp. 215-221, 2017.

[4] Adnan, M., et al., SimMobility: a multi-scale integrated agent-based simulation platform. Transportation Research Board 95th Annual Meeting, pp. 1-18, 2015. 
[5] Heinrichs, D., Autonomous driving and urban land use, Autonomous Driving: Technical, Legal and Social Aspects, eds. M. Maurer, J.C. Gerdes, B. Lenz \& H. Winner. Springer-Verlag: Berlin Heidelberg, pp. 213-231, 2016.

[6] Fraedrich, E., Heinrichs, D., Bahamonde-Birke, F.J. \& Cyganski, R., Autonomous driving, the built environment and policy implications. Transportation Research Part A: Policy and Practice, Mar. 2018.

[7] Grand design of national spatial development towards 2050; Japan Ministry of Land, Infrastructure, Transport and Tourism, http://www.mlit.go.jp/common/ 001088248.pdf (accessed on: 01 Sep. 2018).

[8] Amano, H. \& Uchimura, T., Latest development in sip-adus and related activities in Japan. Road Vehicle Automation 4, eds. G. Meyer and S. Beiker. Springer International Publishing: Cham, pp. 15-24, 2018.

[9] Oshima official statistics; Oshima Town Office, https://www.town.oshima.tokyo.jp/soshiki/seisaku/chosei-soukatsu.html (accessed on: 01 Sep. 2018).

[10] 6th Oshima basic plan; Oshima Town Office, https://www.town.oshima.tokyo. jp/soshiki/seisaku/kihonkeikaku-kihonkousou.html (accessed on: 01 Sep. 2018).

[11] Kagoshima Prefecture island promotion; Kagoshima prefecture remote island promotion council, http://www.pref.kagoshima.jp/ac07/pr/shima/gaiyo/documents/ 43753 _ 20180214145620-1.pdf (accessed on: 01 Sep. 2018).

[12] Toyama's response to demographic evolution: developing a transport-oriented, compact, and livable city; Matamoto K., http://siteresources.worldbank.org/ INTURBANDEVELOPMENT/Resources/336387-1270074782769/6925944-1288991290394/Day2_ P3A_4_Toyama.pdf (accessed on: 01 Sep. 2018).

[13] Levin, M.W., Kockelman, K.M., Boyles, S.D. \& Li, T., A general framework for modeling shared autonomous vehicles with dynamic network-loading and dynamic ridesharing application. Computers, Environment and Urban Systems, 64, pp. 373-383, 2017.

[14] Official statistics of Japan; Statistics Bureau, https://www.e-stat.go.jp (accessed on: 01 Sep. 2018).

[15] Personal trip survey; Tokyo Metropolitan Area Traffic Planning Council, http://www. tokyo-pt.jp/data/01.html (accessed on: 01 Sep. 2018).

[16] Statistical handbook of Japan; Japan Statistics Bureau, http://www.stat.go.jp/english/ data/handbook/index.html (accessed on: 01 Sep. 2018).

[17] Fukuda, K., Age-period-cohort decomposition of U.S. and Japanese birth rates. Population Research and Policy Review, 27(4), pp. 385-402, 2008.

[18] World population prospects: the 2017 revision; UN Population Division, http://data. un.org/Data.aspx?d=PopDiv\&f=variableID\%3A52 (accessed on: 01 Sep. 2018).

[19] Krueger, R., Rashidi, T.H. \& Rose, J.M., Preferences for shared autonomous vehicles. Transportation Research Part C: Emerging Technologies, 69, pp. 343-355, Aug. 2016.

[20] Average service life of buses in Japan from fiscal year 2007 to 2016; Statista, https:// www.statista.com/statistics/679755/japan-bus-average-lifespan/ (accessed on: 01 Sep. 2018).

[21] Average service life of passenger cars in Japan from fiscal year 2007 to 2016; Statista, https://www.statista.com/statistics/679614/japan-passenger-car-average-lifespan/ (accessed on: 01 Sep. 2018). 
[22] Fagnant, D. \& Kockelman, K., Dynamic ride-sharing and fleet sizing for a system of shared autonomous vehicles in Austin, Texas. Transportation, 45(1), pp. 143-158, 2018.

[23] Litman, T., Valuing transit service quality improvements. Journal of Public Transportation, 11(2), pp. 43-63, 2008.

[24] Milakis, D., van Arem, B. \& van Wee, B., Policy and society related implications of automated driving: a review of literature and directions for future research. Journal of Intelligent Transportation Systems, 21(4), pp. 324-348, 2017.

[25] Survey on economic loss of traffic accidents; Japanese Cabinet Office, http://www8. cao.go.jp/koutu/chou-ken/h23/pdf/kekka.pdf (accessed on: 01 Sep. 2018).

[26] Statistical survey on automobile transport; Ministry of Land Infrastructure Transport and Tourism, http://www.mlit.go.jp/k-toukei/jidousya/kekka.html (accessed on: 01 Sep. 2018). 